\title{
Using Electronic Referrals to Address Health Disparities and Improve Blood Pressure Control
}

\author{
Amy Bettano, $\mathrm{MPH}^{1}$; Thomas Land, $\mathrm{PHD}^{2}$; Alice Byrd, MPH${ }^{1}$; Susan Svencer, $\mathrm{MPH}^{3}$; Laura Nasuti, $\mathrm{PHD}^{1}$
}

\begin{abstract}
Accessible Version: www.cdc.gov/pcd/issues/2019/18_0583.htm
Suggested citation for this article: Bettano A, Land T, Byrd A, Svencer S, Nasuti L. Using Electronic Referrals to Address Health Disparities and Improve Blood Pressure Control. Prev Chronic Dis 2019;16:180583. DOI: https://doi.org/10.5888/pcd16.180583.
\end{abstract}

\section{PEER REVIEWED}

\section{Summary}

What is already known about this topic?

Previous electronic referral evaluations focused only on clinical settings and did not examine differences in referral and completion rates by racial/ ethnic groupings and preferred language.

\section{What is added by this report?}

From 2014 through 2017, Massachusetts clinics used electronic referrals to connect underserved patients to community organizations. NonHispanic black and Hispanic patients had higher odds than non-Hispanic white patients of receiving a referral, and patients who completed their hypertension intervention had higher odds of controlled blood pressure.

What are the implications for public health practice?

This research demonstrates that electronic referral systems can successfully direct referrals to community organizations to address health disparities and improve health outcomes.

\section{Abstract}

\section{Introduction}

Massachusetts developed and used bidirectional electronic referrals to connect clinical patients across the state to interventions run by community organizations. The objective of our study was to determine whether the use of Massachusetts's electronic referral system (MA e-Referral) reached racial/ethnic groups experiencing health disparities and whether it was associated with improved health outcomes.

\section{Methods}

We assembled encounter-level medical records from September 2013 through June 2017 for patients at Massachusetts clinics funded by the Clinical Community Partnerships for Prevention into 2 cohorts. First, all patients meeting program eligibility guidelines for an e-Referral $(\mathrm{N}=21,701)$ were examined to assess the distribution of e-Referrals among populations facing health disparities; second, a subset of 3,817 people with hypertension were analyzed to detect changes in blood pressure after e-Referral to an evidencebased community intervention.

\section{Results}

Non-Hispanic black (OR, 1.4; 95\% confidence interval [CI], 1.2-1.6) and Hispanic patients (OR, 1.3; 95\% CI, 1.1-1.4) had higher odds than non-Hispanic white patients of being referred electronically. Patients completing their hypertension intervention had $74 \%$ (95\% CI, 1.2-2.5) higher odds of having an in-control blood pressure reading than patients who were not electronically referred.

\section{Conclusion}

Clinical to community linkage to interventions through MA e-Referral reached non-Hispanic black, Hispanic, and Spanish-speaking populations and was associated with improved blood pressure control.

\section{Introduction}

Racism, classism, sexism, and socioeconomic inequalities prevent people from achieving good health (1). These conditions create health disparities - the variation in health outcomes between groups that are "systematic, socially produced (and therefore modifiable), and unfair" (2). Massachusetts created the Prevention and Wellness Trust Fund to address health disparities and improve health outcomes. Nine communities covering $15 \%$ of the Massachusetts population were granted funding under the fund's Clinical-Community Partnerships for Prevention (CCPP) (3). These communities had $23 \%$ higher rates of hospitalization, greater racial/ethnic diversity, more residents living below the poverty line, and shorter lifespans than the state average (3).

In 2008, Frieden and Mostashari proposed using electronic health records (EHRs) to achieve health improvements (4). Multiple sites and countries previously implemented electronic referrals to link

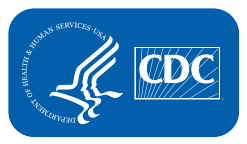

The opinions expressed by authors contributing to this journal do not necessarily reflect the opinions of the U.S. Department of Health and Human Services, the Public Health Service, the Centers for Disease Control and Prevention, or the authors' affiliated institutions. 
primary care to specialists (5-11). Studies of electronic referrals to tobacco cessation services found increased referral rates, uptake of services, and quit rates relative to other referral methods (12-15). Current research has not examined whether different racial/ethnic populations consent at the same rate to electronic referrals, and research is limited on outcomes outside of tobacco use.

In 2013, Massachusetts secured a State Innovation Model Testing Award from the Centers for Medicare and Medicaid Innovation; from that award Massachusetts developed the first fully electronic, bidirectional referral system between clinicians and community resources (16). The Massachusetts e-Referral system deviates from other electronic referral methods in 2 ways: 1) information moves in both directions between the referring provider and the receiving organization, and 2) the organizations receiving referrals are community-based $(16,17)$. All CCPP partnerships were required to implement an e-referral system. The objective of our study was to determine if clinical sites using the MA e-Referral system successfully reached racial/ethnic groups experiencing health disparities. Additionally, our analyses assessed the efficacy of e-Referrals for community organizations in achieving health improvements.

\section{Methods}

Encounter-level health records on all patients at clinics participating in CCPP were the primary data source. These data are sent quarterly to the Massachusetts Department of Public Health to evaluate quality improvement efforts. Each patient is assigned a random identification number to link records. Information collected includes diagnosis codes, medications, demographics (such as self-reported race/ethnicity and preferred language), laboratory values, and vital signs.

MA e-Referral data were captured in a separate database and matched to the clinical records through an outside agency. Information in the MA e-Referral database covered patients referred, the intervention to which they were referred, and their intervention progress. The linked database resulted in a clinical data set of more than 4 million records for 430,085 patients for visits from September 1, 2013, through June 30, 2017; 99\% of electronic referrals were successfully linked to medical records. From this data set, a retrospective cohort analysis was performed on clinical patients in the CCPP. The CCPP program and data were determined to be nonresearch by the Massachusetts Department of Public Health's institutional review board.

Each CCPP partnership was required to implement an electronic referral system in at least 1 clinical site. Ten health center sites representing 8 of the 9 partnerships ( 1 partnership invested in its own electronic referral system) implemented MA e-Referral to connect their patients $(\mathrm{N}=155,454)$ to 13 evidence-based com- munity interventions that ranged from self-monitored blood pressure and chronic disease self-management for hypertension to home visits for patients at risk for falls (details of interventions are in the Prevention and Wellness Trust Fund Legislative Report [3]). Health centers selected which conditions they wanted to address in their populations. People who received a diagnosis of a condition eligible for e-Referral $(n=21,701)$ were separated into those who were electronically referred $(n=1,866)$ to any community program compared with those not electronically referred $(n=19,835)$. Multiple logistic regression models were used to analyze differences in referral patterns and completion rates by race/ethnicity and preferred language; $95 \%$ confidence intervals were used to establish significance (Figure 1).

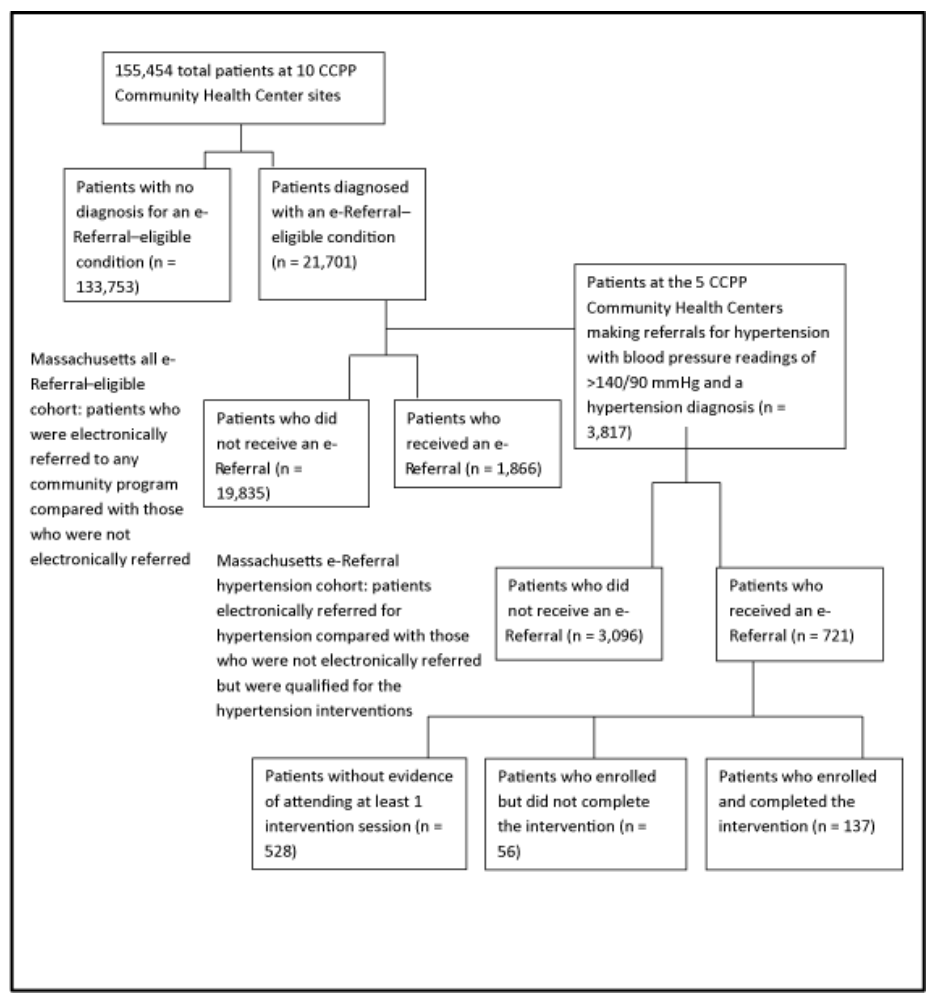

Figure 1. Flowchart of the Massachusetts all e-Referral-eligible cohort and the Massachusetts e-Referral hypertension cohort. The flowchart depicts the progression of the patient population from the 10 Clinical Community Partnerships for Prevention (CCPP) Community Health Center sites to the Massachusetts all e-Referral-eligible cohort $(n=21,701)$ and the Massachusetts e-Referral hypertension cohort $(n=3,817)$.

The second portion of the analysis focused on determining whether health improvements were associated with the delivery of community-based interventions. For these analyses, only people who had or were eligible for hypertension e-Referrals were examined. Blood pressure readings emerged as a primary focus of this ana-

The opinions expressed by authors contributing to this journal do not necessarily reflect the opinions of the U.S. Department of Health and Human Services, the Public Health Service, the Centers for Disease Control and Prevention, or the authors' affiliated institutions. 
lysis because more patients were referred to community services for hypertension than for any other health condition. Patients at the 5 sites addressing hypertension who met eligibility criteria for a hypertension referral on at least 1 visit in the baseline year were divided into those who were electronically referred versus not electronically referred $(n=3,817$ patients in the Massachusetts hypertension cohort sample). The CCPP eligibility criteria for a hypertension referral were having a recorded hypertension diagnosis code during the baseline year and 1 or more blood pressure readings during the baseline year that indicated pressure was not under control $(\geq 140 / 90 \mathrm{mmHg}$ ) per JNC 7 (Joint National Committee on Prevention, Detection, Evaluation, and Treatment of High Blood Pressure-7) guidelines (3). Those receiving hypertension eReferrals (group $1, \mathrm{n}=721$ ) to either self-monitored blood pressure or chronic disease self-management (3) and those who met the criteria but who were not referred (group 2, n =3,096) were compared to assess blood pressure changes over time (Figure 1). Of the 721 patients electronically referred, 528 lacked documented evidence in the e-Referral system of attending at least 1 session of the intervention, 56 individuals were enrolled but did not complete the intervention, and 137 individuals enrolled and completed the intervention. The timeframe for these analyses was individualized to each clinical site: baseline data were defined as the year leading up to the date of the clinic's first e-Referral for hypertension, and intervention data were all post that point. Start dates for hypertension e-Referrals ranged from April through November 2015. The study population was limited to patients with at least 1 follow-up visit during the intervention period.

Sex (male, female, other), self-reported race/ethnicity (non-Hispanic white, non-Hispanic black, Hispanic, other), preferred language for medical information (English, Spanish, other), age group (18-34, 35-54, 55-74, 275), and comorbidities (as defined by the Charlson Comorbidity Index [18,19]) were included in the hypertension models as covariates. The outcomes were blood pressure control status and systolic readings based on the last documented blood pressure during the intervention period. Systolic blood pressure was selected because systolic decreases have a greater impact than diastolic decreases on improving cardiac health outcomes (20-22). These blood pressure readings were analyzed with a multiple logistic regression model to detect transition to controlled blood pressure from baseline through the intervention period, and we used a multiple linear regression model to detect millimeters of mercury $(\mathrm{mmHg})$ changes in systolic blood pressure; $95 \%$ confidence intervals were used to establish significance. SAS version 9.3 (SAS Institute) was used for all analyses performed.

\section{Results}

\section{Demographic comparison of referred patients with other groups}

Although Massachusetts residents are $80 \%$ non-Hispanic white and $16 \%$ speak a language other than English as the primary language at home (3), the demographics of the patient population seen at the 10 clinical sites indicated that the CCPP clinics reached a more diverse population. The 155,454 patients were $36.5 \%$ nonHispanic white, and only slightly more than half preferred to have medical information presented in English (56.1\%) (Table 1). We performed $\chi^{2}$ tests of independence on both the all e-Referral-eligible cohort and the e-Referral hypertension cohort; the distribution of demographics in each sample was related to referral status.

E-Referrals were first made in 2014. From 2014 through 2017, 1,866 patients received at least one e-Referral. All race/ethnicity and language referral analyses controlled for age category, sex, and Charlson comorbidity presence. Among these referrals, Hispanic patients had $26 \%$ higher odds of being electronically referred than non-Hispanic white patients $(95 \% \mathrm{CI}, 1.1-1.4)$ and non-Hispanic black patients had 37\% higher odds (95\% CI, 1.2-1.6) (Figure 2).

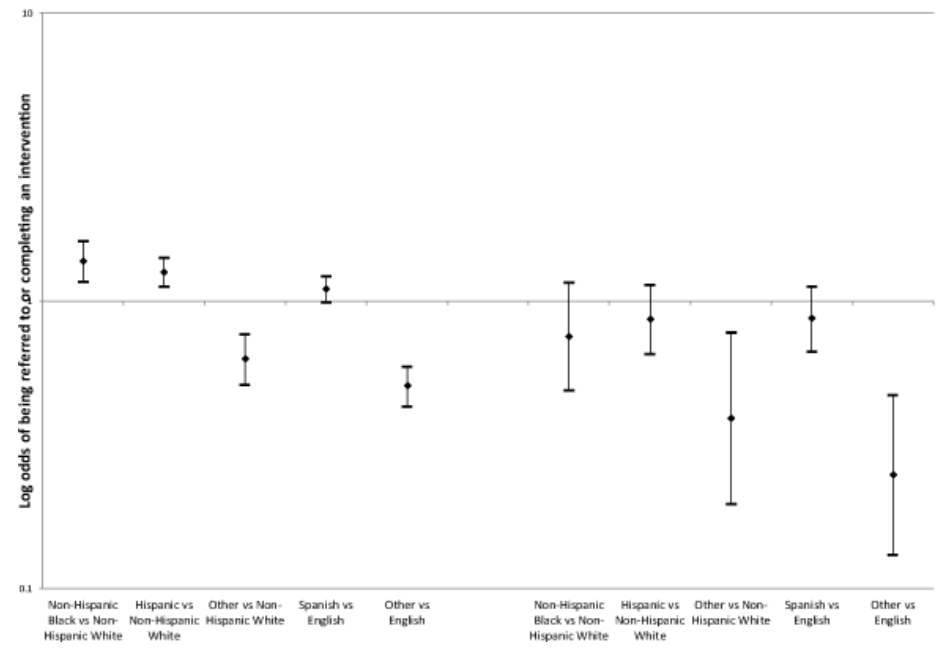

Figure 2. Multiple logistic regression modeling of the odds of receiving and completing an e-Referral by race/ethnicity and preferred language among 21,701 Massachusetts clinical patients seen from 2013 through 2017. The multiple logistic regression models examine the odds of referral and the odds of completing an intervention by race/ethnicity and preferred language. Brackets indicate $95 \%$ Wald confidence intervals. Abbreviation: $\mathrm{NH}$, nonHispanic.

Next, completion rates were examined with logistic regression models of race/ethnicity and preferred language that controlled for

\footnotetext{
The opinions expressed by authors contributing to this journal do not necessarily reflect the opinions of the U.S. Department of Health and Human Services, the Public Health Service, the Centers for Disease Control and Prevention, or the authors' affiliated institutions.
} 
age category, sex, and Charlson comorbidity status to determine whether all groups had the same odds of completing interventions once they were electronically referred. Completion rates among Hispanic patients (OR 0.9; 95\% CI, 0.7-1.1) and non-Hispanic black patients (OR $0.8 ; 95 \%$ CI, 0.5-1.2) were not significantly different from non-Hispanic white patients' completion rates. By language, completion rates among Spanish speakers and English speakers were also not significantly different (OR $0.9 ; 95 \%$ CI, 0.7-1.1) (Figure 2).

\section{Hypertension health outcomes of referred patients compared with nonreferred patients}

A multiple logistic regression model was used to calculate the odds that an individual maintained or achieved blood pressure control $(<140 / 90 \mathrm{mmHg})$ at their last reading during the intervention time period when compared with their last reading during baseline. During the last visit of the baseline period, $62 \%$ of the nonreferred group had hypertensive blood pressure compared with $58 \%$ of the electronically referred group. After controlling for sex, presence of comorbidities, age group, race/ethnicity, and preferred language, patients who were electronically referred (regardless of the referral outcome) had $66 \%$ greater odds $(95 \% \mathrm{CI}$, 1.4-2.0) of maintaining or achieving blood pressure control when compared with nonreferred patients. Patients who were referred and completed their program had $74 \%$ greater odds $(95 \% \mathrm{CI}$, $1.2-2.5)$ than nonreferred patients of moving into or maintaining blood pressure control (Table 2). At the end of the intervention period, $43 \%$ of the nonreferred group had hypertensive blood pressure compared with $33 \%$ of the electronically referred group $(P<$ $.01)$. When controlling for referral and completion status, non-Hispanic black patients had lower odds of achieving blood pressure control than non-Hispanic white patients, whereas Hispanic patients and Spanish-speaking patients did not have significantly different rates of control achievement than non-Hispanic white patients and English-speaking patients (Table 2). All groups saw a decrease in the percentage of their population with hypertensive blood pressure readings, but only for Hispanic and non-Hispanic white patients was the difference in the referred group significantly lower than in the nonreferred group $(P<.01$ for both).

To determine the extent of changes in systolic blood pressure readings, the final systolic readings were compared among the groups in a linear regression. During the last visit of the baseline period, the nonreferred group had an average systolic blood pressure reading of $139 \mathrm{mmHg}$, compared with $138 \mathrm{mmHg}$ in the electronically referred group. After controlling for sex, Charlson comorbidities, age group, race/ethnicity, and preferred language, patients who were referred (regardless of the referral outcome) had a final systolic blood pressure reading that was on average 3.4 mmHg lower $(P<.01)$ than patients without a referral. When lim- iting the referral sample to only completers, referred patients who completed their intervention had a final systolic blood pressure reading that was on average $3.0 \mathrm{mmHg}$ lower $(P=.04)$ than patients without a referral (Table 3 ). At the end of the intervention period, the nonreferred group had an average systolic blood pressure reading of $134 \mathrm{mmHg}$ compared with $131 \mathrm{mmHg}$ in the electronically referred group. Non-Hispanic black patients had a higher final systolic blood pressure than non-Hispanic white patients. Hispanic patients did not have significantly different systolic blood pressure readings than non-Hispanic white patients, nor did Spanish-speaking patients have significantly different systolic blood pressure readings than English-speaking patients (Table 3). All racial/ethnic referred groups, except for non-Hispanic white patients, saw an average decrease in their systolic blood pressure readings that was more than double what was observed in their nonreferred counterparts.

\section{Discussion}

Electronic referrals have been found to better ensure the delivery of referrals, improve documentation, and standardize the referral format when compared with other referral methods (5-9). Embedding referral information in medical records provided the opportunity to assess the efficacy of MA e-Referral as a bidirectional referral system establishing clinical to community linkages (7). Moreover, MA e-Referral allowed Massachusetts to assess whether referrals were being directed toward groups experiencing health disparities. Nationally, hypertension is a prominent health equity issue. Rates among non-Hispanic black people in the United States are among the highest worldwide, and this population develops high blood pressure at younger ages than non-Hispanic white populations and has higher average blood pressure levels (23), which persist even after controlling for socioeconomic status and underlying medical conditions $(24,25)$. Our analysis controlled for the presence of comorbidities, which are correlated with hypertension rates and cluster in populations to produce some of the hypertension health disparities (26). People with 1 or more comorbidities were $30 \%$ more likely to have in-control blood pressure.

Promisingly, our analysis found that referrals were successfully focused on groups facing hypertension health disparities: among eligible candidates, non-Hispanic black and Hispanic patients had higher odds of receiving an e-Referral than non-Hispanic white patients. The MA e-Referral system allowed for examination of completion rates by race/ethnicity to determine whether e-Referrals led to participation in community programs. Completion rates by race/ethnicity and language were not significantly different when compared with non-Hispanic white patients or with Englishspeaking patients' completion rates.

\footnotetext{
The opinions expressed by authors contributing to this journal do not necessarily reflect the opinions of the U.S. Department of Health and Human Services, the Public Health Service, the Centers for Disease Control and Prevention, or the authors' affiliated institutions.
} 
Both receiving and completing an e-Referral for a community hypertension intervention were found to be correlated with increased likelihood of achieving blood pressure control and reducing systolic blood pressure. The $3.0 \mathrm{mmHg}$ reduction in systolic blood pressure that referral completers experienced is on par with the reductions seen in many nonpharmacologic interventions promoted by the 2017 High Blood Pressure Clinical Practice Guidelines (26).

This research had some limitations. First, although all clinical sites received guidelines on how to refer patients, there was flexibility in guideline application. If patients did not conform to referral criteria, but clinical judgment determined that the program would be valuable, a referral could be made. Data indicate the guidelines were typically observed, because $74 \%$ of hypertension e-Referral patients met JNC 7 guidelines before referral. The nonreferred group, all of whom met JNC 7 guidelines, may not accurately represent the health status of the electronically referred patients (in the absence of a referral). Furthermore, the offer of an e-Referral to patients was not documented in medical records. Because accepting an e-Referral intervention was voluntary, participating patients may have been more motivated to make behavior changes to reduce their hypertension risk beyond intervention participation, potentially introducing self-selection bias (28). Additionally, our clinics are relatively homogenous in serving low-income populations that were racially, ethnically, and linguistically diverse. The linear modeling outlined in this article was also run as a mixed-effects model with clinic as a random effect; clinical effect was not significant. Though it did not affect the model, the unique makeup of our clinical populations may limit generalizability of the results. Lastly, the MA e-Referral system was designed to facilitate communication between clinicians and community service providers rather than as a data collection system for research. Consequently, we had issues with the standardization of the MA e-Referral data for the term "enrollment." All e-Referrals were reviewed by the first author to systematize the classification of enrollment as at least 1 session attended. Not all sites were able to implement e-Referral because of technology or budget limitations and instead made referrals via paper copies and fax. These referrals were not used in this analysis. However, data collected on all methods of hypertension referrals to community interventions established the enrollment rate at approximately 50\% (3). Even after reclassification, this analysis found only a $27 \%$ referral enrollment rate. It is unclear if more patients enrolled than were able to be identified on the basis of the documentation in the e-Referral system. Future analyses of the benefits of enrolling (even without completion) would expand the evidence base around the effectiveness of these interventions.

Patients completing interventions to which they were referred had higher odds of transitioning to an in-control blood pressure status and of experiencing reductions in their overall systolic blood pressure when compared with nonreferred patients with similar demographic and health profiles. Additionally, e-Referrals were successfully directed toward groups facing health disparities, and completion rates were not statistically different between groups after the e-Referral was made. These findings demonstrate the successful implementation of the MA e-Referral system as a means to connect patients to evidence-based interventions to improve hypertension outcomes and of the ability to direct referrals to address health disparities, both critical steps toward improved population health.

\section{Acknowledgments}

The project was supported by Funding Opportunity Number CMS1G1-12-001 from the U.S. Department of Health and Human Services, Centers for Medicare and Medicaid Services, and the Prevention and Wellness Trust Fund (established by the Massachusetts Legislature through Chapter 224 of the Acts of 2012). Work was done at the Massachusetts Department of Public Health. The contents provided are solely the responsibility of the authors and do not necessarily represent the official views of HHS (or any of its agencies) or the Massachusetts Department of Public Health. The e-Referral system was financed $80 \%$ from the Center for Medicaid and Medicare Innovation ( $\$ 4.3$ million) and 20\% from Massachusetts' Chapter 224 funding (\$990,000) over 2014-2018.

\section{Author Information}

Corresponding Author: Amy Bettano, Massachusetts Department of Public Health, 250 Washington St, 6th floor, Boston, MA 02108. Telephone: 617-624-5467. Email: amy.bettano@state.ma.us

Author Affiliations: ${ }^{1}$ Massachusetts Department of Public Health, Boston, Massachusetts. ${ }^{2}$ Department of Medicine, University of Massachusetts Medical School, Worcester, Massachusetts.

${ }^{3}$ National Association of Chronic Disease Directors, Decatur, Georgia.

\section{References}

1. Hofrichter R, editor. Tackling health inequities through public health practice: a handbook for action. The National Association of County and City Health Officials and The Ingham County Health Department; 2006 [cited 2017 Nov 9]. Available from: http://nccdh.ca/resources/entry/tacklinghealth-inequities. Accessed November 9, 2017.

The opinions expressed by authors contributing to this journal do not necessarily reflect the opinions of the U.S. Department of Health and Human Services, the Public Health Service, the Centers for Disease Control and Prevention, or the authors' affiliated institutions. 
2. Whitehead M, Dahlgren G. Concepts and principles for tackling social inequities in health: levelling up part 1 . World Health Organization Regional Office for Europe; 2006. http:// www.euro.who.int/_data/assets/pdf_file/0010/74737/ E89383.pdf. Accessed November 9, 2018.

3. The Massachusetts Prevention and Wellness Trust Fund 2017 Legislative Report. Massachusetts: Bureau of Community Health and Prevention, Massachusetts Department of Public Health; 2017. https://mapublichealth.org/wp-content/uploads/ 2019/02/PWTF_AnnualReport_2017_interactive_02.17.171.pdf. Accessed August 8, 2017.

4. Frieden TR, Mostashari F. Health care as if health mattered. JAMA 2008;299(8):950-2.

5. Singh H, Esquivel A, Sittig DF, Murphy D, Kadiyala H, Schiesser R, et al. Follow-up actions on electronic referral communication in a multispecialty outpatient setting. J Gen Intern Med 2011;26(1):64-9.

6. Naseriasl M, Adham D, Janati A. E-referral solutions: Successful experiences, key features and challenges - a systematic review. Mater Sociomed 2015;27(3):195-9.

7. Tuot DS, Leeds K, Murphy EJ, Sarkar U, Lyles CR, Mekonnen $\mathrm{T}$, et al. Facilitators and barriers to implementing electronic referral and/or consultation systems: a qualitative study of 16 health organizations. BMC Health Serv Res 2015;15(1):568.

8. Shaw LJ, de Berker DA. Strengths and weaknesses of electronic referral: comparison of data content and clinical value of electronic and paper referrals in dermatology. $\mathrm{Br} \mathrm{J}$ Gen Pract 2007;57(536):223-4.

9. Esquivel A, Sittig DF, Murphy DR, Singh H. Improving the effectiveness of electronic health record-based referral processes. BMC Med Inform Decis Mak 2012;12(1):107.

10. Hysong SJ, Esquivel A, Sittig DF, Paul LA, Espadas D, Singh $\mathrm{S}$, et al. Towards successful coordination of electronic health record based-referrals: a qualitative analysis. Implement Sci 2011;6(1):84.

11. Warren J, White S, Day KJ, Gu Y, Pollock M. Introduction of electronic referral from community associated with more timely review by secondary services. Appl Clin Inform 2011; 2(4):546-64.

12. Ray MN, Funkhouser E, Williams JH, Sadasivam RS, Gilbert GH, Coley HL, et al.; National Dental PBRN Collaborative Group. Smoking-cessation e-referrals: a national dental practice-based research network randomized controlled trial. Am J Prev Med 2014;46(2):158-65.

13. Adsit RT, Fox BM, Tsiolis T, Ogland C, Simerson M, Vind LM, et al. Using the electronic health record to connect primary care patients to evidence-based telephonic tobacco quitline services: a closed-loop demonstration project. Transl Behav Med 2014;4(3):324-32.
14. Land TG, Rigotti NA, Levy DE, Schilling T, Warner D, Li W. The effect of systematic clinical interventions with cigarette smokers on quit status and the rates of smoking-related primary care office visits. PLoS One 2012;7(7):e41649.

15. Warner D, Land T, Rodgers A, Keithly L. Integrating tobacco cessation quitlines into health care: Massachusetts, 2002-2011. Prev Chronic Dis 2012;9(E133).

16. RTI International, National Academy for State Health Policy, The Urban Institute. State Innovation Models (SIM) initiative evaluation: model test year three annual report. Baltimore (MD): Centers for Medicare and Medicaid Services; 2017 Sept. Report No.:0212790.007. Contract No.: HHSM-5002010-002li. https://downloads.cms.gov/files/cmmi/sim-rd1mtthirdannrpt.pdf. Accessed November 9, 2018.

17. Nasuti L. Formalizing community-clinical relationships: ereferral program. Presentation for the Massachusetts Public Health Council; 2015 March. http://blog.mass.gov/ publichealth/wp-content/uploads/sites/11/2016/03/ereferral.pdf. Accessed January 7, 2019.

18. Charlson M, Szatrowski TP, Peterson J, Gold J. Validation of a combined comorbidity index. J Clin Epidemiol 1994; 47(11):1245-51.

19. Quan H, Sundararajan V, Halfon P, Fong A, Burnand B, Luthi $\mathrm{J}-\mathrm{C}$, et al. Coding algorithms for defining comorbidities in ICD-9-CM and ICD-10 administrative data. Med Care 2005; 43(11):1130-9.

20. Kannel WB, Gordon T, Schwartz MJ. Systolic versus diastolic blood pressure and risk of coronary heart disease. The Framingham Study. Am J Cardiol 1971;27(4):335-46.

21. Wang JG, Staessen JA, Franklin SS, Fagard R, Gueyffier F. Systolic and diastolic blood pressure lowering as determinants of cardiovascular outcome. Hypertension 2005;45(5):907-13.

22. Haider AW, Larson MG, Franklin SS, Levy D; Framingham Heart Study. Systolic blood pressure, diastolic blood pressure, and pulse pressure as predictors of risk for congestive heart failure in the Framingham Heart Study. Ann Intern Med 2003; 138(1):10-6.

23. Mozaffarian D, Benjamin EJ, Go AS, Arnett DK, Blaha MJ, Cushman $M$ et al; American Heart Association Statistics Committee; Stroke Statistics Subcommittee. Heart disease and stroke statistics - 2016 update: a report from the American Heart Association. Circulation 2016;133(4):e38-360.

24. Delgado J, Jacobs EA, Lackland DT, Evans DA, de Leon CF. Differences in blood pressure control in a large populationbased sample of older African Americans and non-Hispanic whites. J Gerontol A Biol Sci Med Sci 2012;67(11):1253-8.

25. Redmond N, Baer HJ, Hicks LS. Health behaviors and racial disparity in blood pressure control in the National Health and Nutrition Examination Survey. Hypertension 2011; 57(3):383-9.

\footnotetext{
The opinions expressed by authors contributing to this journal do not necessarily reflect the opinions of the U.S. Department of Health and Human Services, the Public Health Service, the Centers for Disease Control and Prevention, or the authors' affiliated institutions.
} 
26. Opara F, Hawkins K, Sundaram A, Merchant M, Rasmussen S, Holmes L Jr. Impact of comorbidities on racial/ethnic disparities in hypertension in the United States. ISRN Public Health;2013:1-8.

27. Whelton PK, Carey RM, Aronow WS, Casey DE Jr, Collins KJ, Dennison Himmelfarb C, et al. 2017 ACC/AHA/AAPA/ ABC/ACPM/AGS/APHA/ASH/ASPC/NMA/PCNA guideline for the prevention, detection, evaluation, and management of high blood pressure in adults: executive summary: a report of the American College of Cardiology/American Heart Association Task Force on clinical practice guidelines. Hypertension 2018;71(6):1269-324. . Errata in:Hypertension. 2018;71(6):e136-e139 and Hypertension 2018;72(3):e33.

28. Tripepi G, Jager KJ, Dekker FW, Zoccali C. Selection bias and information bias in clinical research. Nephron Clin Pract 2010; 115(2):c94-9.

The opinions expressed by authors contributing to this journal do not necessarily reflect the opinions of the U.S. Department of Health and Human Services, the Public Health Service, the Centers for Disease Control and Prevention, or the authors' affiliated institutions. 


\section{Tables}

Table 1. Characteristics of Patients in the Massachusetts e-Referral Program, September 2013-June $2017^{a}$

\begin{tabular}{|c|c|c|c|c|c|}
\hline \multirow[b]{2}{*}{ Variable } & \multirow{2}{*}{$\begin{array}{l}\text { All Clinical Patients at } \\
\text { e-Referral Sites (\%) }\end{array}$} & \multicolumn{2}{|c|}{ All e-Referral-Eligible Cohort (\%) } & \multicolumn{2}{|c|}{ e-Referral Hypertension Cohort (\%) } \\
\hline & & Not Referred & Referred & Not Referred & Referred \\
\hline Total Population & $155,454(100.0)$ & $19,835(91.4)$ & $1866(8.6)$ & $3,096(81.1)$ & $721(18.9)$ \\
\hline \multicolumn{6}{|l|}{ Race/ethnicity } \\
\hline Non-Hispanic black & $16,233(10.4)$ & $2,027(10.2)$ & $237(12.7)$ & $379(12.4)$ & $127(17.6)$ \\
\hline Hispanic & $59,000(38.0)$ & $7,754(39.1)$ & $918(49.2)$ & $1,263(40.8)$ & $390(54.1)$ \\
\hline Non-Hispanic white & $56,702(36.5)$ & $7,375(37.2)$ & $583(31.2)$ & $1,096(35.4)$ & $161(22.3)$ \\
\hline Other ${ }^{b}$ & 23,519 (15.1) & $2,679(13.5)$ & $128(6.9)$ & $358(11.6)$ & $43(6.0)$ \\
\hline \multicolumn{6}{|l|}{ Sex } \\
\hline Male & $68,572(44.1)$ & $8,937(45.1)$ & $715(38.3)$ & $1,599(51.7)$ & $432(59.9)$ \\
\hline Female & $86,874(55.9)$ & $10,897(54.9)$ & $1,151(61.7)$ & $1,497(48.4)$ & $289(40.1)$ \\
\hline Other & $8(0.0)$ & $1(0.0)$ & $0(0.0)$ & $0(0.0)$ & $0(0.0)$ \\
\hline \multicolumn{6}{|l|}{ Preferred language $^{c}$} \\
\hline English & $87,218(56.1)$ & $9,476(47.8)$ & $878(47.1)$ & $1,445(46.7)$ & $354(49.1)$ \\
\hline Spanish & $41,495(26.7)$ & $6,290(31.7)$ & $783(42.0)$ & $1,063(34.3)$ & $338(46.9)$ \\
\hline Other & $26,741(17.2)$ & $4,069(20.5)$ & 205 (11.0) & $588(19.0)$ & $29(4.0)$ \\
\hline$\geq 1$ Charlson comorbidities present $^{d}$ & $34,310(22.1)$ & $10,465(52.8)$ & $1,397(74.9)$ & 2,355 (76.1) & $553(76.7)$ \\
\hline \multicolumn{6}{|l|}{ Age } \\
\hline $0-17$ & $36,378(23.4)$ & $1,140(5.8)$ & $77(4.1)$ & $0(0.0)$ & $0(0.0)$ \\
\hline $18-34$ & $42,143(27.1)$ & $1,007(5.1)$ & $121(6.5)$ & $72(2.3)$ & $17(2.4)$ \\
\hline $35-54$ & $45,757(29.4)$ & $4,763(24.0)$ & $504(27.0)$ & $1,017(32.9)$ & $245(34.0)$ \\
\hline $55-74$ & $27,024(17.4)$ & $10,032(50.6)$ & $917(49.1)$ & $1,675(54.1)$ & $423(58.7)$ \\
\hline$\geq 75$ & $4,152(2.7)$ & $2,893(14.6)$ & $247(13.2)$ & $332(10.7)$ & $36(5.0)$ \\
\hline
\end{tabular}

${ }^{a}$ Percentages may not total 100 because of rounding.

${ }^{\mathrm{b}}$ Includes all patients not classified as non-Hispanic black, Hispanic, or non-Hispanic white.

${ }^{\mathrm{c}}$ The primary language that the patient selects to receive medical information.

${ }^{d}$ Charlson comorbidity index $(18,19)$. 
Table 2. Comparison of 2 Models for Odds of Blood Pressure Control During the Intervention, Patients in Massachusetts e-Referral Program, September 2013-June $2017^{\mathrm{a}}$

\begin{tabular}{|c|c|c|}
\hline Variable & $\begin{array}{l}\text { Model 1: All Massachusetts e-Referral for Hypertension } \\
\text { Patients and Patients Not e-Referred }(n=3,817), \text { OR }(95 \% \\
\text { Cl) }\end{array}$ & $\begin{array}{l}\text { Model 2: Patients Completing Massachusetts e-Referral for } \\
\text { Hypertension and Patients Not e-Referred }(n=3,233) \text {, OR } \\
\qquad(95 \% \mathrm{Cl})^{\mathrm{a}}\end{array}$ \\
\hline \multicolumn{3}{|l|}{ Race/ethnicity } \\
\hline Non-Hispanic white & & Reference \\
\hline Non-Hispanic black & $0.7(0.6-0.9)$ & $0.8(0.6-1.0)$ \\
\hline Hispanic & $0.8(0.6-1.0)$ & $0.9(0.7-1.2)$ \\
\hline Other ${ }^{b}$ & $1.0(0.8-1.3)$ & $1.0(0.8-1.4)$ \\
\hline \multicolumn{3}{|l|}{ Age, y } \\
\hline $18-34$ & & Reference \\
\hline $35-54$ & $0.7(0.4-1.0)$ & $0.6(0.4-1.0)$ \\
\hline $55-74$ & $0.8(0.5-1.2)$ & $0.7(0.4-1.2)$ \\
\hline$\geq 75$ & $0.8(0.5-1.3)$ & $0.7(0.4-1.3)$ \\
\hline \multicolumn{3}{|l|}{ Preferred language $^{c}$} \\
\hline English & & Reference \\
\hline Other & $1.1(0.9-1.4)$ & $1.1(0.9-1.4)$ \\
\hline Spanish & $1.1(0.9-1.4)$ & $1(0.8-1.3)$ \\
\hline \multicolumn{3}{|l|}{ Sex } \\
\hline Male & & Reference \\
\hline Female & $1.1(1.0-1.3)$ & $1.1(1.0-1.3)$ \\
\hline \multicolumn{3}{|l|}{ Comorbidity $^{d}$} \\
\hline Absent & & Reference \\
\hline Present & $1.3(1.1-1.5)$ & $1.3(1.1-1.6)$ \\
\hline \multicolumn{3}{|l|}{ Referral status $^{e}$} \\
\hline No referral & & Reference \\
\hline Referred & $1.7(1.4-2.0)$ & $-^{f}$ \\
\hline Completed referral & $-^{f}$ & $1.7(1.2-2.5)$ \\
\hline
\end{tabular}

Abbreviations: $\mathrm{Cl}$, confidence interval; OR, odds ratio.

${ }^{a}$ Multiple logistic regression model of the odds ratios for last blood pressure transitioning to or remaining in control when compared with baseline blood pressure in the Massachusetts e-Referral hypertension cohort population. Values are odds ratio and 95\% confidence intervals for in-control blood pressure. Wald $95 \%$ confidence intervals were used to establish significance.

${ }^{b}$ Includes all patients not classified as non-Hispanic black, Hispanic, or non-Hispanic white.

${ }^{\mathrm{c}}$ The primary language that the patient selects to receive medical information.

${ }^{d}$ Defined as the presence of hypertension and 1 or more of the conditions covered by the Charlson comorbidity index $(18,19)$.

${ }^{e}$ Defined as whether patients received an e-Referral and whether they completed that e-Referral.

${ }^{f}$ Outcome not applicable for that logistic regression model. 
Table 3. Comparison of Systolic Blood Pressure Measurements During the Intervention, Calculated by Multiple Linear Regression, Patients in Massachusetts eReferral Program, April 2015-June 2017

\begin{tabular}{|c|c|c|c|c|}
\hline \multirow[b]{2}{*}{ Characteristic } & \multicolumn{2}{|c|}{$\begin{array}{l}\text { Model 1: All MA e-Referred for Hypertension Patients and } \\
\text { Not e-Referred }(n=3,817)\end{array}$} & \multicolumn{2}{|c|}{$\begin{array}{l}\text { Model 2: Only Completing MA e-Referral for Hypertension } \\
\text { Patients and Not-e-Referred }(n=3,233)\end{array}$} \\
\hline & $\begin{array}{l}\text { Mean Change in Systolic } \\
\text { Blood Pressure (mmHg) }\end{array}$ & $P$ Value $^{\mathrm{a}}$ & $\begin{array}{l}\text { Mean Change in Systolic } \\
\text { Blood Pressure (mmHg) }\end{array}$ & $P$ Value $^{\mathrm{a}}$ \\
\hline \multicolumn{5}{|l|}{ Race/ethnicity } \\
\hline Non-Hispanic white & \multicolumn{4}{|r|}{ Reference } \\
\hline Non-Hispanic black & 3.2 & $<.001$ & 3.0 & .001 \\
\hline Hispanic & 0.9 & .38 & -0.3 & .77 \\
\hline Other ${ }^{b}$ & -0.07 & .94 & 0.4 & .73 \\
\hline \multicolumn{5}{|l|}{ Age } \\
\hline $18-34$ & \multicolumn{4}{|r|}{ Reference } \\
\hline $35-54$ & 2.9 & .1 & 3.7 & .06 \\
\hline $55-74$ & 4.6 & .01 & 5.2 & .01 \\
\hline$\geq 75$ & 5.2 & .01 & 5.5 & .01 \\
\hline \multicolumn{5}{|l|}{ Preferred language $^{c}$} \\
\hline English & \multicolumn{4}{|r|}{ Reference } \\
\hline Other & 0.3 & .72 & 0.06 & .94 \\
\hline Spanish & -0.3 & .73 & 0.7 & .52 \\
\hline \multicolumn{5}{|l|}{ Sex } \\
\hline Male & \multicolumn{4}{|r|}{ Reference } \\
\hline Female & -1.5 & .01 & -1.0 & .09 \\
\hline \multicolumn{5}{|l|}{ Comorbidity $^{\mathrm{d}}$} \\
\hline Absent & \multicolumn{4}{|r|}{ Reference } \\
\hline Present & -1.8 & .005 & -2.0 & .004 \\
\hline \multicolumn{5}{|l|}{ Referral status $^{\mathrm{e}}$} \\
\hline No referral & \multicolumn{4}{|r|}{ Reference } \\
\hline Referred & -3.4 & $<.001$ & $-^{f}$ & $-{ }^{f}$ \\
\hline Completed referral & $-^{f}$ & $--^{f}$ & -3.0 & .04 \\
\hline
\end{tabular}

${ }^{a} P$ values calculated by using $t$ test; $\alpha$ level for significance was $P<.05$.

${ }^{\mathrm{b}}$ Includes all patients not classified as non-Hispanic black, Hispanic, or non-Hispanic white.

${ }^{\mathrm{c}}$ The primary language that the patient selects to receive medical information.

${ }^{d}$ Defined as the presence of hypertension and 1 or more of the conditions covered by the Charlson comorbidity index $(18,19)$.

${ }^{\mathrm{e}}$ Defined as whether patients received an e-Referral and whether they completed that e-Referral.

${ }^{f}$ Outcome not applicable for that linear regression model. 